\title{
Long-term drying of Mars by sequestration of ocean-scale volumes of water in the crust
}

\author{
E. L. Scheller ${ }^{*}$, B. L. Ehlmann",2, Renyu Hu², D. J. Adams', Y. L. Yungi,2

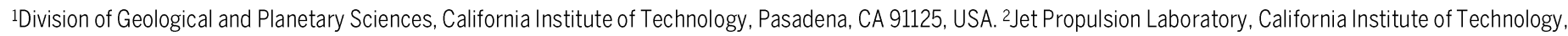 \\ Pasadena, CA 91109, USA.
}

*Corresponding author. Email: eschelle@caltech.edu

Geological evidence shows that ancient Mars had large volumes of liquid water. Models of past hydrogen escape to space, calibrated with observations of the current escape rate, cannot explain the present-day $\mathrm{D} / \mathrm{H}$ isotope ratio. We simulate volcanic degassing, atmospheric escape, and crustal hydration on Mars, incorporating observational constraints from spacecraft, rovers and meteorites. We find ancient water volumes equivalent to a 100- to 1500-meter global layer are simultaneously compatible with the geological evidence, loss rate estimates, and $\mathrm{D} / \mathrm{H}$ measurements. In our model, the volume of water participating in the hydrological cycle decreased by 40 to $95 \%$ over the Noachian period ( -3.7 to 4.1 billion years ago), reaching present-day values by $\sim 3.0$ billion years ago. Between 30 and $99 \%$ of Martian water was sequestered by crustal hydration, demonstrating that irreversible chemical weathering can increase the aridity of terrestrial planets.

There is abundant geomorphological evidence for large volumes of surface liquid water early in Martian history (1), with estimated volumes equivalent to a 100 to $1500 \mathrm{~m}$ deep global equivalent layer (GEL) (1-4). Liquid water on Mars decreased over geological time; presently most water is stored in the polar ice caps or as subsurface ice. Estimates for the total modern water inventory, in the atmosphere and as ice, total 20-40 m GEL (5-8). The availability of water to participate in the hydrologic cycles of terrestrial planets is expected to influence their climate and habitability. However, the processes that caused the decline of available water on Mars are poorly constrained.

Previous studies have suggested that Mars experienced substantial water loss due to atmospheric escape, supported by the current atmospheric deuterium to hydrogen isotope ratio $(\mathrm{D} / \mathrm{H})$ of 5-10 $\times$ SMOW (Standard Mean Ocean Water on Earth; D/H at $1 \mathrm{SMOW}$ is $\left.155.76 \times 10^{-6}\right)(5,9-11)$. The $\mathrm{D} / \mathrm{H}$ value at $\sim 4$ Ga was $2-4 \times$ SMOW, inferred from Martian meteorites (fig. S1) (12, 13). Existing models used these observations, combined with assumed atmospheric escape fractionation factors ( $\left.\alpha_{\text {escape }}\right)$ of 0.016-0.32 during loss, to estimate integrated atmospheric escape of at least 10-200 m GEL (fig. S1) $(4,5,11,14,15)$. These estimates imply an initial 50240 m GEL water on ancient Mars, consistent only with the lower range of geological estimates (100-1500 m GEL) (1-4). This has been interpreted as implying a large, unknown reservoir of water on present-day Mars (4).

For present-day Mars, the rate of atmospheric water loss is measured from the $\mathrm{H}$ escape flux, because water vapor dissociates and its hydrogen escapes. Spacecraft measurements of the current $\mathrm{H}$ escape flux, 1 to $11 \times 10^{26} \mathrm{H}$ atoms s $\mathrm{s}^{-1}$, are equivalent to escape of 3-25 m GEL water over $4.5 \mathrm{Ga}(16,17)$ and cannot explain all the water loss. Another potential water loss mechanism is crustal hydration through irreversible chemical weathering, in which water and/or hydroxyl are incorporated into minerals. Orbital and in situ data show that widespread chemical weathering has produced a substantial reservoir of hydrous minerals on Mars, potentially totaling hundreds of meters GEL in the crust $(5,18)$. We hypothesize that crustal hydration during the first 1-2 billion years decreased the volume of the hydrologically-available water reservoir, followed by subsequent atmospheric loss that fractionated the Martian atmosphere to its current observed $\mathrm{D} / \mathrm{H}$ ratio. We simulate water loss through geological time to constrain Mars' water history and compare the simulations to $\mathrm{D} / \mathrm{H}$ data from the Curiosity rover (5) and laboratory analyses of Martian meteorites (fig. S1) $(12,13,19,20,21)$.

\section{A hydrogen isotope water reservoir model}

We developed a water budget and $\mathrm{D} / \mathrm{H}$ model that integrates water sinks and sources, including crustal hydration, volcanic degassing and atmospheric escape (Fig. 1) (5). Most previous models included only atmospheric escape $(4,11,14)$; one model (15) also included volcanic degassing. We treat liquid water, ice, and atmospheric vapor as a single exchangeable reservoir, an isotopic modelling technique originally developed for carbon reservoir models (22). We assume that liquid and solid phases, not vapor, dominate the exchangeable reservoir and fractionation between them is negligible [the fractionation factor is $\alpha_{\text {ice-liquid }}=1.02$ (23)]. Our 
simulations are constrained such that the exchangeable reservoir can never be negative and must reproduce $20-40 \mathrm{~m}$ GEL water today. The initial exchangeable reservoir size $\left(X_{\mathrm{ex}, 0}\right)$, i.e., the ancient hydrologically available water inventory, is a free parameter except during sensitivity analyses. We determined permitted ranges of source and sink fluxes for crustal hydration $\left(F_{\text {crust }}\right)$, volcanic degassing $\left(F_{\text {volcanic }}\right)$, and atmospheric escape $\left(F_{\text {esc }}\right)$ during the Noachian $(\sim 4.0-3.7 \mathrm{Ga})$, Hesperian $(\sim 3.7-3.0 \mathrm{Ga})$, and Amazonian ( 3.0 Ga to present) periods of Martian geological history following observational and previous model constraints (Fig. 1 and table S1) (5). Models were evaluated by their ability to reproduce the $\mathrm{D} / \mathrm{H}$ ratio of the present-day exchangeable reservoir $\left(R_{\text {ex,end }}\right)$ of 5 $10 \times$ SMOW. We also compare our simulation results to a compilation of Curiosity rover Sample Analysis at Mars (SAM) data sets that record a $\mathrm{D} / \mathrm{H}$ composition range of 3-5 $\times$ SMOW for gas released from Hesperian samples during high temperature $\left(>374^{\circ} \mathrm{C}\right)$ combustion experiments (5).

We calculate a permitted range of $F_{\text {crust }}$ from measurements of $\mathrm{H}$ wt.\% in Mars surface materials and global remote sensing observations of hydrated minerals. The mass fraction of crustal $\mathrm{H}_{2} \mathrm{O}$ is based on rover measurements from Gale crater, orbital global infrared and neutron spectrometer data, and measurements of the NWA 7034 Martian meteorite (0.5$3 \mathrm{wt} \% \mathrm{H}_{2} \mathrm{O}$ ) (5). The volume of the crustal reservoir is based on orbital measurements of clay exposure depths in the Valles Marineris canyon and craters $5-10 \mathrm{~km}$ in depth $(5,18)$. We adopt permitted ranges of 100-900 m GEL of water in Noachian-aged crust and 10-100 m GEL in Hesperian-aged crust based on this analysis (table $\mathrm{S} 1)(5,18)$. Although $F_{\text {crust }}$ is based on observations of hydrated minerals, we consider crustal water as a single reservoir representing any combination of ice and liquid water, formerly participating in the hydrologic cycle, that now no longer exchange isotopes with the exchangeable reservoir. $F_{\text {volcanic }}$ is determined using previous thermochemical models of the Martian mantle (24). Different parameterizations of those models (24) predict outgassing of 10-120 m GEL $\mathrm{H}_{2} \mathrm{O}$ from volcanic processes since $4.1 \mathrm{Ga}$ (5, 24). We consider Noachian and Hesperian $F_{\text {esc }}$ values between $10^{25}$ and $10^{30} \mathrm{H}$ atoms s $\mathrm{s}^{-1}$ and adopt the measured current escape rate of $5 \times 10^{26} \mathrm{H}$ atoms s${ }^{-1}$ for the Amazonian (table S1) (5). These escape fluxes are compared to simulations using the $1 \mathrm{D}$ photochemical model Kinetics $(25,26)$ with adopted past solar extreme ultraviolet flux, variable atmospheric pressures, mesospheric and surface temperatures (table S2) (5).

\section{Controls on $\mathrm{D} / \mathrm{H}$ and water loss}

In our model, step-wise mixing between the exchangeable reservoir and the depleted volcanically outgassed water vapor $(0.8-2 \times$ SMOW $)$ (fig. S1 and table S1) $(5,19,27)$ causes the $\mathrm{D} / \mathrm{H}$ of the exchangeable reservoir to decrease (5). We do not include fractionation associated with degassing or its redox sensitivity as these are negligible compared to the large range of potential $\mathrm{D} / \mathrm{H}$ compositions of the volcanic gas inferred from meteorites (5). Atmospheric escape causes $\mathrm{D} / \mathrm{H}$ of the exchangeable reservoir to fractionate toward heavier values, which we modeled through stepwise Rayleigh distillation, a common isotopic reservoir modelling technique, at each 10Myr time step with a fractionation factor of atmospheric escape $\left(\alpha_{\text {escape }}\right)$ of $0.002-0.32(28-30)$. The fractionation factor between smectite, the most common hydrated mineral found on Mars, and water $\left[\alpha_{\text {smectite } \mathrm{H}_{2} \mathrm{O}}=0.95\right.$ (5) $]$ is used in the step-

wise Rayleigh distillation model as a first order approximation of fractionation by crustal hydration (table S3) (5); we find this fractionation is minor compared to that caused by atmospheric escape.

The $\mathrm{D} / \mathrm{H}$ of the exchangeable reservoir increases during the Noachian in all our simulations, and through the Hesperian in most of them, due to a combination of crustal hydration and atmospheric escape (Figs. 2 and 3). Higher $F_{\text {esc,N }}$ and $F_{\text {esc, } \mathrm{H}}$ increase $\mathrm{D} / \mathrm{H}$ fractionations of the exchangeable reservoirs (Fig. 2, A and B). We find that the Noachian and Hesperian $\mathrm{H}$ escape flux ranges that satisfy the model constraints (fig. S2) have a wide allowable range, $\sim 0.1-1000 \times$ the current $5 \times 10^{26} \mathrm{H}$ atoms $\mathrm{s}^{-1}$ escape flux. Independently, our Kinetics photochemical simulations (5) produce the same range $\left(\sim 10^{25}\right.$ to $5 \times 10^{29} \mathrm{H}$ atoms s${ }^{-1}$ ) (fig. S3). We considered multiple scenarios including (i) a range of standard ancient Mars conditions, (ii) high-altitude water injection (60 ppm at $100 \mathrm{~km}$ ), and (iii) fixing a surface $\mathrm{H}_{2}$ mixing ratio of $10^{-3}$, higher than present-day levels of $10^{-5}(26)$. The maximum Kinetics-permitted escape flux $\left.\left(\sim 5 \times 10^{29} \mathrm{H} \text { atoms s}\right)^{-1}\right)$ and our $\mathrm{D} / \mathrm{H}$ model maximum permitted flux $\left(4 \times 10^{29} \mathrm{H}\right.$ atoms s $\left.\mathrm{s}^{-1}\right)$ match the diffusion-limited escape of $5 \times 10^{29} \mathrm{H}$ atoms $\mathrm{s}^{-1}$ we calculate, using equations from (31). The injection of high-altitude water and increased surface $\mathrm{H}_{2}$ concentrations both increase the production of high-altitude $\mathrm{H}_{2}$; one or both would be required for loss fluxes 100-1000 $\times$ higher than present (fig. S3).

Crustal hydration during early Mars history also increases $\mathrm{D} / \mathrm{H}$ fractionation of the exchangeable reservoirs, with the permitted range of $F_{\text {crust, }}$ depending on the assumed $F_{\text {crust,H }}$ (Fig. 2C). This is primarily because higher $F_{\text {crust, } \mathrm{N}}$ decreases the exchangeable reservoir size, not because of the fractionation $\left[\alpha_{\text {smectite- } \mathrm{H}_{2} \mathrm{O}}=0.95\right.$ (5) $]$ associated with clay formation. As the exchangeable reservoir is reduced through crustal hydration, less atmospheric escape is needed to produce the modern $\mathrm{D} / \mathrm{H}$ of the atmosphere. During the Noachian, decreasing exchangeable reservoir size and increasing $\mathrm{D} / \mathrm{H}$ are a feature of all our simulations. Changes to the assumed timing of the boundary between the Noachian and Hesperian $\left(t_{\mathrm{N}-\mathrm{H}}\right)$ and balance of $F_{\text {crust, } \mathrm{N}}$ to $F_{\text {crust,H }}$ only slightly affect the Noachian $\mathrm{D} / \mathrm{H}$ fractionation (Figs. $2 \mathrm{C}$ and $3 \mathrm{C}$ ). During the Amazonian, the exchangeable reservoir size is low, and its $\mathrm{D} / \mathrm{H}$ increases 
slightly in all our simulations due to the lack of crustal hydration, low $\mathrm{H}$ escape flux (assumed equal to the present rate), and a low volcanic degassing flux (Figs. 2 and 3). In contrast, the $\mathrm{D} / \mathrm{H}$ evolution during the Hesperian is less well constrained because models with low total volcanic outgassing (10-20 m GEL) result in $\mathrm{D} / \mathrm{H}$ increases while models with high outgassing (60-120 m GEL) result in $\mathrm{D} / \mathrm{H}$ decreasing or staying approximately constant (Fig. 3, A and B). The amount of volcanic degassing controls the required sizes of $F_{\text {crust }}$ and $F_{\text {esc }}$ for different $X_{\mathrm{ex}, 0}$ to reproduce the present-day D/H ratio ( $R_{\text {ex,end }}$ (figs. S4 to S6). Evolution of Hesperian D/H is also sensitive to the absolute timing of the debated (5) boundary between the Hesperian and Amazonian periods $\left(t_{\mathrm{H}-\mathrm{A}}\right)$ because in our model that boundary sets the hydration and volcanic flux magnitudes (Fig. 3C).

\section{Crustal hydration as a water sink}

Considering the simulations over our whole parameter space, we find that the amounts of water lost through crustal hydration and atmospheric escape vary in ratios ranging from 3:8 to 99:1 (Fig. 4 and figs. S4 to S6), equivalent to $~ 30-$ $99 \%$ of initial water being lost through crustal hydration (5). The maximum proportional contribution of atmospheric escape occurs when the volume of the crustal water reservoir is minimum and vice versa. Any larger proportional escape would produce $\mathrm{D} / \mathrm{H}$ heavier than the present-day observed value $(>10 \times$ SMOW). However, the absolute allowed volumes of integrated crustal hydration and atmospheric escape are dependent on the size of the initial exchangeable reservoir (figs. S4 to S6). For some of our model solutions, no difference in the average atmospheric escape flux relative to the presentday flux is required to account for the observed increase in $\mathrm{D} / \mathrm{H}$ and decrease in the exchangeable water reservoir (Fig. 4 and figs. S3 and S4). Both the maximum and minimum escape-to-space cases (Fig. 4 and figs. S4 to S6) occur with intermediate assumed initial exchangeable reservoir volumes ( 500 $\mathrm{m}$ GEL).

Accounting for water loss by both crustal hydration and atmospheric escape (figs. S4 to S6) resolves the apparent contradiction between the estimates of integrated $\mathrm{H}$ escape, the $\mathrm{D} / \mathrm{H}$ ratio of present-day Mars, and geological estimates of a large, ancient exchangeable reservoir $(1,4)$. These can be reconciled because the amount of atmospheric escape needed for the atmosphere to reach the present-day $\mathrm{D} / \mathrm{H}$ ratio is reduced by the removal of large initial water volumes via crustal hydration. Our models require larger Noachian exchangeable reservoirs (100-1500 m GEL) than previous work (50-240 m GEL) because we include crustal hydration (Fig. 4F). The whole parameter space allows for initial exchangeable water reservoirs of 100-1500 m GEL at 4.1 Ga, 20$300 \mathrm{~m}$ GEL at the Noachian/Hesperian boundary, and a nearconstant 20-40 m GEL throughout the Amazonian (Fig. 4F).
We chose a preferred solution based on observational constraints on the parameter space (Table 1 and Fig. 4F). In this preferred simulation, the Noachian and Hesperian H escape fluxes are twice that of today, i.e., $F_{\mathrm{esc}, \mathrm{N}}=F_{\mathrm{esc}, \mathrm{H}} \sim 10^{27} \mathrm{H}$ atoms $\mathrm{s}^{-1}$. The Kinetics simulations indicate that the most probable long-term $\mathrm{H}$ escape flux was similar to today, though there may have been shorter duration enhancements e.g., during dust storms or surface fluxes of $\mathrm{H}_{2}$ from geologic processes (5) (figs. S2 and S3). In the preferred model, crustal hydration removes $500 \mathrm{~m}$ GEL and $50 \mathrm{~m}$ GEL during the Noachian and Hesperian, respectively, corresponding to roughly $3 \mathrm{wt} \% \mathrm{H}_{2} \mathrm{O}$ in Noachian crust of $5 \mathrm{~km}$ thickness and 1 wt\% $\mathrm{H}_{2} \mathrm{O}$ in Hesperian crust of $1 \mathrm{~km}$ thickness (18). This is compatible with the range of present-day water contents and crustal reservoir depths measured from orbit and rovers (5). $F_{\text {volcanic }}$ is assumed based on volcanic degassing simulations (24) which themselves assumed $f_{\text {mantle }}=100 \mathrm{ppm}$ based on meteorite measurements (5). This is compatible with observational constraints on crustal production rates and water contents of Martian meteorites (5). Our preferred simulation is therefore similar to the minimum escape case shown in Fig. 4C. These simulations adopt $R_{\mathrm{ex}, 0}=4 \times$ SMOW based on meteorite measurements (5) and produce a present-day $\mathrm{D} / \mathrm{H}$ ratio of $\sim 5.3 \times$ SMOW.

\section{Consequences for Mars evolution}

If the planet accreted with $0.1-0.2$ wt\% water (32), the large Noachian exchangeable reservoirs predicted by the model are consistent with Mars primordial water volumes. A Martian primordial volume of $>1100 \mathrm{~m}$ GEL (potentially thousands of meters GEL) could have been produced by catastrophic outgassing of the mantle ( $500-6000 \mathrm{~m}$ GEL) (33, $34)$, delivery of water through impacts (600-2700 m GEL) (35), and/or capture of gasses from the protoplanetary disc (36). However, the high hydrogen loss rates indicated by the $\mathrm{D} / \mathrm{H}$ ratio at $4.1 \mathrm{Ga}$ recorded within meteorites $(4,11)$ and possible evidence for hydrodynamic escape in Xe isotopes (37) suggest that a large part of the primordial atmosphere and water were lost during the pre-Noachian period. Our proposed volumes of 100-1500 m GEL during the early Noachian are within the lower end of these predicted primordial volumes and would therefore be compatible with the loss of a large part of the primordial atmosphere. Following loss of the primordial atmosphere, isotope measurements of $\mathrm{C}$ and $\mathrm{Ar}$ suggest that loss of a large fraction of these elements from the remaining Martian atmosphere and the reservoirs that exchange with the atmosphere would have occurred after 4.1 $\mathrm{Ga}(19,37-39)$. This matches our proposed trajectory of water loss within the exchangeable reservoir, which is reduced by 80-99\% after $4.1 \mathrm{Ga}$ within our model simulations.

Our modeled initial reservoirs are also consistent with geological estimates of Noachian and Hesperian surface water 
volumes. A 100-150 m GEL ocean during the Hesperian $(1,40)$ has been suggested from geomorphological observations and is compatible with our preferred simulation. A larger $550 \mathrm{~m}$ GEL ocean that has been suggested at the Noachian/Hesperian boundary (3) is possible in simulations where $F_{\text {crust }}$ and $F_{\text {esc }}$ are both maximized in the Noachian and Hesperian, requiring the initial exchangeable water reservoir at $4.1 \mathrm{Ga}$ to be $~ 1500 \mathrm{~m}$ GEL (Fig. 4F). Even larger oceans of 1000-1500 m GEL have been proposed based on geomorphology $(1,2)$; these would be permitted only in certain simulation scenarios during the early Noachian and not later epochs (Fig. 4F).

Our models are compatible with the major observed trajectories of Martian climate. A high volume Noachian exchangeable reservoir is consistent with geomorphological evidence for large volumes of Noachian surface waters and observed widespread hydrated mineral formation. Aqueous alteration of the crust could have produced periods of warmer and wetter climates (supplementary text) (41-43) through accumulation of $\mathrm{H}_{2}$ in the atmosphere (figs. $\mathrm{S} 4$ to S6). In cases where atmospheric escape dominates water loss over the crustal hydration sink, $\mathrm{H}$ loss could be balanced by atmospheric oxygen escape (18-58 m GEL) and crustal oxidation ( $\sim 30-380 \mathrm{~m}$ GEL) (supplementary text). However in cases where crustal hydration dominates water loss, shortterm accumulation of $\mathrm{H}_{2}$ could have occurred (supplementary text). In our Kinetics simulations, the accumulation of $\mathrm{H}_{2}$ in the atmosphere results in increased $\mathrm{H}$ escape flux (fig. S3) (5).

The permitted parameter space of our $\mathrm{D} / \mathrm{H}$ model allows either (i) a Hesperian exchangeable reservoir that was initially large but smaller than the Noachian reservoir $(\leq 300 \mathrm{~m}$ GEL) and decreased or (ii) a Hesperian reservoir that was similar to present-day levels of 20-40 m GEL (Fig. 4F). In case (i), the Hesperian may have had sustained periods of warm and wet climate, which could have caused chemical weathering on a global scale and potentially formed an ocean $(1,40)$. In case (ii), the Hesperian climate was likely similar to the Amazonian climate with the exception of few local and shortlived instances of surface liquid water reservoirs (44). During the Amazonian period, the low $\mathrm{H}$ escape flux and low volcanic degassing flux counter each other, producing low model water availability within the exchangeable reservoir consistent with geomorphological and mineralogical evidence of an arid climate (Fig. 4F) (31, 45).

Crustal hydration would produce a buried water reservoir with composition reflecting the Noachian exchangeable reservoir of $\sim 2-4 \times$ SMOW. Martian meteorites with ages of 1.6 to $0.1 \mathrm{Ga}$ have D/H values of $\sim 2-3 \times \mathrm{SMOW}(20,21)$. Previously proposed explanations include a distinct subsurface fluid reservoir, mixing between low $\mathrm{D} / \mathrm{H}$ igneous and high D/H present-day atmospheric material, or terrestrial contamination $(20,21)$. We suggest that exchange between younger igneous rocks and fluids derived from hydrated Noachian $(\sim 2-4 \times$ SMOW $)$ crust could account for the intermediate $\mathrm{D} / \mathrm{H}$ in these meteorites.

\section{Comparative planetary evolution}

We conclude that the increasing aridity of Mars over its history was caused by the sink of chemical weathering of the crust (Fig. 4), recorded in the widespread Noachian hydrated minerals on the planet's surface (18). On Earth, crustal hydration also occurs but plate tectonics enables recycling of crustal water that is eventually outgassed to the atmosphere through volcanism (46). This has facilitated sustained participation of water in the hydrologic cycle throughout geological history on Earth (46). The ancient age of most hydrated minerals (43) indicates that any such recycling did not persist on Mars. Irreversible chemical weathering therefore plays a role in regulating the habitability of terrestrial planets, by controlling the timescales of sustained participation of water in the hydrologic cycle.

Our model makes testable predictions for $\mathrm{D} / \mathrm{H}$ measurements of the rock and ice record (Figs. 2 and 3): a substantial long-term secular increase in $\mathrm{D} / \mathrm{H}$ over the Noachian and potentially Hesperian with little change over the Amazonian. Under a variable climate, our model also indicates the geological record might contain evidence of short-term $\mathrm{D} / \mathrm{H}$ cyclicity: transient warm periods with greater atmospheric $\mathrm{H}_{2} \mathrm{O}$ (42) would periodically increase crustal hydration and escape flux, rapidly increasing $\mathrm{D} / \mathrm{H}$, whereas during cold periods, the $\mathrm{D} / \mathrm{H}$ would decrease or increase slowly, depending on the balance between volcanic degassing and atmospheric escape.

\section{REFERENCES AND NOTES}

1. M. H. Carr, J. W. Head, Oceans on Mars: An assessment of the observational evidence and possible fate. J. Geophys. Res. Planets 108, 5042 (2003). doi:10.1029/2002JE001963

2. S. M. Clifford, T. J. Parker, The evolution of the Martian hydrosphere: Implications for the fate of a primordial ocean and the current state of the northern plains. Icarus 154, 40-79 (2001). doi:10.1006/icar.2001.6671

3. G. Di Achille, B. M. Hynek, Ancient ocean on mars supported by global distribution of deltas and valleys. Nat. Geosci. 3, 459-463 (2010). doi:10.1038/ngeo891

4. H. Kurokawa, M. Sato, M. Ushioda, T. Matsuyama, R. Moriwaki, J. M. Dohm, T. Usui, Evolution of water reservoirs on Mars: Constraints from hydrogen isotopes in Martian meteorites. Earth Planet. Sci. Lett. 394, 179-185 (2014). doi:10.1016/i.epsl.2014.03.027

5. Materials and methods are available as supplementary materials.

6. M. T. Zuber, D. E. Smith, S. C. Solomon, J. B. Abshire, R. S. Afzal, O. Aharonson, K. Fishbaugh, P. G. Ford, H. V. Frey, J. B. Garvin, J. W. Head, A. B. Ivanov, C. L. Johnson, D. O. Muhleman, G. A. Neumann, G. H. Pettengill, R. J. Phillips, X. Sun, H. J. Zwally, W. B. Banerdt, T. C. Duxbury, Observations of the north polar region of Mars from the Mars orbiter laser altimeter. Science 282, 2053-2060 (1998) doi:10.1126/science.282.5396.2053 Medline

7. J. J. Plaut, G. Picardi, A. Safaeinili, A. B. Ivanov, S. M. Milkovich, A. Cicchetti, W. Kofman, J. Mouginot, W. M. Farrell, R. J. Phillips, S. M. Clifford, A. Frigeri, R. Orosei, C. Federico, I. P. Williams, D. A. Gurnett, E. Nielsen, T. Hagfors, E. Heggy, E. R. Stofan, D. Plettemeier, T. R. Watters, C. J. Leuschen, P. Edenhofer, Subsurface radar sounding of the south polar layered deposits of Mars. Science 316, 92-95 (2007). doi:10.1126/science.1139672 Medline 
8. P. R. Christensen, Water at the poles and in permafrost regions of Mars. Elements 2,151-155 (2006). doi:10.2113/gselements.2.3.151

9. T. M. Donahue, Evolution of water reservoirs on Mars from $\mathrm{D} / \mathrm{H}$ ratios in the atmosphere and crust. Nature 374, 432-434 (1995). doi:10.1038/374432a0 Medline

10. C. R. Webster et al., Isotope ratios of $\mathrm{H}, \mathrm{C}$, and $\mathrm{O}$ in $\mathrm{CO}_{2}$ and $\mathrm{H}_{2} \mathrm{O}$ of the martian atmosphere. Science 341, 260-263 (2013). doi:10.1126/science.1237961 Medline

11. G. L. Villanueva, M. J. Mumma, R. E. Novak, H. U. Käufl, P. Hartogh, T. Encrenaz, A. Tokunaga, A. Khayat, M. D. Smith, Strong water isotopic anomalies in the martian atmosphere: Probing current and ancient reservoirs. Science 348, 218-221 (2015). doi:10.1126/science.aaa3630 Medline

12. N. Z. Boctor, C. M. O. D. Alexander, J. Wang, E. Hauri, The sources of water in Martian meteorites: Clues from hydrogen isotopes. Geochim. Cosmochim. Acta 67, 3971-3989 (2003). doi:10.1016/S0016-7037(03)00234-5

13. J. P. Greenwood, S. Itoh, N. Sakamoto, E. P. Vicenzi, H. Yurimoto, Hydrogen isotope evidence for loss of water from Mars through time. Geophys. Res. Lett. 35, L05203 (2008). doi:10.1029/2007GL032721

14. H. Lammer, C. Kolb, T. Penz, U. V. Amerstorfer, H. K. Biernat, B. Bodiselitsch, Estimation of the past and present Martian water-ice reservoirs by isotopic constraints on exchange between the atmosphere and the surface. Int. J. Astrobiol. 2, 195-202 (2003). doi:10.1017/S1473550403001605

15. N. R. Alsaeed, B. M. Jakosky, Mars water and D/H from $3.3 \mathrm{Ga}$ to present. J. Geophys. Res. Planets 124, 3344-3353 (2019). doi:10.1029/2019JE006066

16. B. M. Jakosky et al., Loss of the Martian atmosphere to space: Present-day loss rates determined from MAVEN observations and integrated loss through time. Icarus 315, 146-157 (2018). doi:10.1016/j.icarus.2018.05.030

17. M. A. Chaffin, J.-Y. Chaufray, I. Stewart, F. Montmessin, N. M. Schneider, J.-L. Bertaux, Unexpected variability of Martian hydrogen escape. Geophys. Res. Lett. 41, 314-320 (2014). doi:10.1002/2013GL058578

18. J. F. Mustard, Sequestration of volatiles in the Martian crust through hydrated minerals: A significant planetary reservoir of water, in Volatiles in the Martian Crust (Elsevier, ed. 2, 2019), pp. 247-264.

19. L. A. Leshin, Insights into Martian water reservoirs from analyses of Martian meteorite QUE94201. Geophys. Res. Lett. 27, 2017-2020 (2000). doi:10.1029/1999GL008455

20. T. Usui, C. M. O. D. Alexander, J. Wang, J. I. Simon, J. H. Jones, Meteoritic evidence for a previously unrecognized hydrogen reservoir on Mars. Earth Planet. Sci. Lett. 410, 140-151 (2015). doi:10.1016/i.epsl.2014.11.022

21. Y. Liu, Y. Chen, Y. Guan, C. Ma, G. R. Rossman, J. M. Eiler, Y. Zhang, Impact-melt hygrometer for Mars: The case of shergottite Elephant Moraine (EETA) 79001. Earth Planet. Sci. Lett. 490, 206-215 (2018). doi:10.1016/j.epsl.2018.03.019

22. R. Hu, D. M. Kass, B. L. Ehlmann, Y. L. Yung, Tracing the fate of carbon and the atmospheric evolution of Mars. Nat. Commun. 6, 10003 (2015). doi:10.1038/ncomms10003 Medline

23. T. Chacko, D. R. Cole, J. Horita, Equilibrium oxygen, hydrogen, and carbon isotope fractionation factors applicable to geologic systems. Rev. Mineral. 43, 1-81 (2001). doi:10.2138/gsrmg.43.1.1

24. M. Grott, A. Morschhauser, D. Breuer, E. Hauber, Volcanic outgassing of $\mathrm{CO}_{2}$ and $\mathrm{H}_{2} \mathrm{O}$ on Mars. Earth Planet. Sci. Lett. 308, 391-400 (2011). doi:10.1016/i.epsl.2011.06.014

25. M. Allen, Y. L. Yung, J. W. Waters, Vertical transport and photochemistry in the terrestrial mesosphere and lower thermosphere (50-120 km). J. Geophys. Res. Space Phys. 86 (A5), 3617-3627 (1981). doi:10.1029/JA086iA05p03617

26. H. Nair, M. Allen, A. D. Anbar, Y. L. Yung, R. T. Clancy, A photochemical model of the martian atmosphere. Icarus 111, 124-150 (1994). doi:10.1006/icar.1994.1137 Medline

27. P. Gillet, J. A. Barrat, E. Deloule, M. Wadhwa, A. Jambon, V. Sautter, B. Devouard D. Neuville, K. Benzerara, M. Lesourd, Aqueous alteration in the Northwest Africa 817 (NWA 817) Martian meteorite. Earth Planet. Sci. Lett. 203, 431-444 (2002). doi:10.1016/S0012-821X(02)00835-X

28. E. Cangi, M. S. Chaffin, J. Deighan, Higher martian atmospheric temperatures at all altitudes increase the D/H fractionation factor and water loss. J. Geophys. Res. Planets 125, (2020). doi:10.1029/2020JE006626

29. V. Krasnopolsky, On the deuterium abundance on Mars and some related problems. Icarus 148, 597-602 (2000). doi:10.1006/icar.2000.6534
30. Y. L. Yung, J.-S. Wen, J. P. Pinto, M. Allen, K. K. Pierce, S. Paulson, HDO in the Martian atmosphere: Implications for the abundance of crustal water. Icarus 76, 146-159 (1988). doi:10.1016/0019-1035(88)90147-9 Medline

31. J. F. Kasting, J. B. Pollack, Loss of water from Venus. I. Hydrodynamic escape of hydrogen. Icarus 53, 479-508 (1983). doi:10.1016/0019-1035(83)90212-9

32. R. Brasser, The formation of Mars: Building blocks and accretion time scale. Space Sci. Rev. 174, 11-25 (2013). doi:10.1007/s11214-012-9904-2

33. L. T. Elkins-Tanton, Linked magma ocean solidification and atmospheric growth for Earth and Mars. Earth Planet. Sci. Lett. 271, 181-191 (2008) doi:10.1016/i.epsl.2008.03.062

34. N. V. Erkaev, H. Lammer, L. T. Elkins-Tanton, A. Stökl, P. Odert, E. Marcq, E. A. Dorfi, K. G. Kislyakova, Y. N. Kulikov, M. Leitzinger, M. Güdel, Escape of the martian protoatmosphere and initial water inventory. Planet. Space Sci. 98, 106-119 (2014). doi:10.1016/i.pss.2013.09.008 Medline

35. J. Lunine, J. Chambers, A. Morbidelli, L. A. Leshin, The origin of water on Mars. Icarus 165, 1-8 (2003). doi:10.1016/S0019-1035(03)00172-6

36. H. Lammer, E. Chassefière, Ö. Karatekin, A. Morschhauser, P. B. Niles, O. Mousis, P. Odert, U. V. Möstl, D. Breuer, V. Dehant, M. Grott, H. Gröller. E. Hauber, L. B. S. Pham, Outgassing history and escape of the Martian atmosphere and water inventory. Space Sci. Rev. 174, 113-154 (2013). doi:10.1007/s11214-012-9943-8

37. B. M. Jakosky, J. H. Jones, The history of Martian volatiles. Rev. Geophys. 35, 1-16 (1997). doi:10.1029/96RG02903

38. S. K. Atreya, M. G. Trainer, H. B. Franz, M. H. Wong, H. L. K. Manning, C. A. Malespin, P. R. Mahaffy, P. G. Conrad, A. E. Brunner, L. A. Leshin, J. H. Jones, C. R. Webster, T. C. Owen, R. O. Pepin, R. Navarro-González, Primordial argon isotope fractionation in the atmosphere of Mars measured by the SAM instrument on Curiosity and implications for atmospheric loss. Geophys. Res. Lett. 40, 56055609 (2013). doi:10.1002/2013GL057763 Medline

39. B. M. Jakosky, M. Slipski, M. Benna, P. Mahaffy, M. Elrod, R. Yelle, S. Stone, N. Alsaeed, Mars' atmospheric history derived from upper-atmosphere measurements of ${ }^{38} \mathrm{Ar} / 36 \mathrm{Ar}$. Science 355, 1408-1410 (2017) doi:10.1126/science.aai7721 Medline

40. M. H. Carr, J. Head, Mars: Formation and fate of a frozen Hesperian ocean. Icarus 319, 433-443 (2019). doi:10.1016/i.icarus.2018.08.021

41. R. D. Wordsworth, The climate of early Mars. Annu. Rev. Earth Planet. Sci. 44, 381408 (2016). doi:10.1146/annurev-earth-060115-012355

42. R. D. Wordsworth, L. Kerber, R. T. Pierrehumbert, F. Forget, J. W. Head, Comparison of "warm and wet" and "cold and icy" scenarios for early Mars in a 3D climate model. J. Geophys. Res. Planets 120, 1201-1219 (2015). doi:10.1002/2015JE004787

43. N. J. Tosca, I. A. M. Ahmed, B. M. Tutolo, A. Ashpitel, J. A. Hurowitz, Magnetite authigenesis and the warming of early Mars. Nat. Geosci. 11, 635-639 (2018). doi:10.1038/s41561-018-0203-8 Medline

44. J. P. Grotzinger, S. Gupta, M. C. Malin, D. M. Rubin, J. Schieber, K. Siebach, D. Y. Sumner, K. M. Stack, A. R. Vasavada, R. E. Arvidson, F. Calef 3rd, L. Edgar, W. F. Fischer, J. A. Grant, J. Griffes, L. C. Kah, M. P. Lamb, K. W. Lewis, N. Mangold, M. E. Minitti, M. Palucis, M. Rice, R. M. E. Williams, R. A. Yingst, D. Blake, D. Blaney, P. Conrad, J. Crisp, W. E. Dietrich, G. Dromart, K. S. Edgett, R. C. Ewing, R. Gellert, J. A. Hurowitz, G. Kocurek, P. Mahaffy, M. J. McBride, S. M. McLennan, M. Mischna, D. Ming, R. Milliken, H. Newsom, D. Oehler, T. J. Parker, D. Vaniman, R. C. Wiens, S. A. Wilson, Deposition, exhumation, and paleoclimate of an ancient lake deposit, Gale crater, Mars. Science 350, aac7575 (2015). doi:10.1126/science.aac7575 Medline

45. B. L. Ehlmann, J. F. Mustard, S. L. Murchie, J.-P. Bibring, A. Meunier, A. A. Fraeman, Y. Langevin, Subsurface water and clay mineral formation during the early history of Mars. Nature 479, 53-60 (2011). doi:10.1038/nature10582 Medline

46. H. Lammer, J. H. Bredehöft, A. Coustenis, M. L. Khodachenko, L. Kaltenegger, O. Grasset, D. Prieur, F. Raulin, P. Ehrenfreund, M. Yamauchi, J.-E. Wahlund, J.-M. Grießmeier, G. Stangl, C. S. Cockell, Y. N. Kulikov, J. L. Grenfell, H. Rauer, What makes a planet habitable? Astron. Astrophys. Rev. 17, 181-249 (2009). doi:10.1007/s00159-009-0019-z

47. T. Usui, C. M. O. D. Alexander, J. Wang, J. I. Simon, J. H. Jones, Origin of water and mantle-crust interactions on Mars inferred from hydrogen isotopes and volatile element abundances of olivine-hosted melt inclusions of primitive shergottites. Earth Planet. Sci. Lett. 357-358, 119-129 (2012). doi:10.1016/j.epsl.2012.09.008 
48. S. Nerozzi, J. W. Holt, Buried ice and sand caps at the north pole of Mars: Revealing a record of climate change in the cavi unit with SHARAD. Geophys. Res. Lett. 46, 7278-7286 (2019). doi:10.1029/2019GL082114

49. J. L. Whitten, B. A. Campbell, Lateral continuity of layering in the Mars South Polar Layered Deposits from SHARAD sounding data. J. Geophys. Res. Planets 123, 1541-1554 (2018). doi:10.1029/2018JE005578

50. J. F. Mustard, C. D. Cooper, M. K. Rifkin, Evidence for recent climate change on Mars from the identification of youthful near-surface ground ice. Nature 412, 411414 (2001). doi:10.1038/35086515 Medline

51. C. M. Dundas, A. M. Bramson, L. Ojha, J. J. Wray, M. T. Mellon, S. Byrne, A. S. McEwen, N. E. Putzig, D. Viola, S. Sutton, E. Clark, J. W. Holt, Exposed subsurface ice sheets in the Martian mid-latitudes. Science 359, 199-201 (2018). doi:10.1126/science.aao1619 Medline

52. A. M. Bramson, S. Byrne, J. Bapst, Preservation of midlatitude ice sheets on Mars. J. Geophys. Res. Planets 122, 2250-2266 (2017). doi:10.1002/2017JE005357

53. N. B. Karlsson, L. S. Schmidt, C. S. Hvidberg, Volume of Martian midlatitude glaciers from radar observations and ice flow modeling. Geophys. Res. Lett. 42. 2627-2633 (2015). doi:10.1002/2015GL063219

54. T. Owen, J. P. Maillard, C. de Bergh, B. L. Lutz, Deuterium on Mars: The Abundance of HDO and the Value of D/H. Science 240, 1767-1767 (1988). doi:10.1126/science. 240.4860 .1767 Medline

55. L. A. Leshin et al., Volatile, isotope, and organic analysis of martian fines with the Mars Curiosity rover. Science 341, 1238937 (2013). doi:10.1126/science.1238937 Medline

56. S. Hu, Y. Lin, J. Zhang, J. Hao, L. Feng, L. Xu, W. Yang, J. Yang, NanoSIMS analyses of apatite and melt inclusions in the GRV 020090 Martian meteorite: Hydrogen isotope evidence for recent past underground hydrothermal activity on Mars. Geochim. Cosmochim. Acta 140, 321-333 (2014). doi:10.1016/igca.2014.05.008

57. D. A. Fisher, Mars' water isotope (D/H) history in the strata of the North Polar Cap: Inferences about the water cycle. Icarus 187, 430-441 (2007). doi:10.1016/i.icarus.2006.10.032

58. F. Montmessinet al., Origin and role of water ice clouds in the Martian water cycle as inferred from a general circulation model.J. Geophys. Res. Planets 109, E10004 (2004). doi:10.1029/2004.JE002284

59. P. R. Mahaffy, C. R. Webster, J. C. Stern, A. E. Brunner, S. K. Atreya, P. G. Conrad, S. Domagal-Goldman, J. L. Eigenbrode, G. J. Flesch, L. E. Christensen, H. B. Franz, C. Freissinet, D. P. Glavin, J. P. Grotzinger, J. H. Jones, L. A. Leshin, C. Malespin, A. C. McAdam, D. W. Ming, R. Navarro-Gonzalez, P. B. Niles, T. Owen, A. A. Pavlov, A. Steele, M. G. Trainer, K. H. Williford, J. J. Wray; MSL Science Team, Mars atmosphere. The imprint of atmospheric evolution in the $\mathrm{D} / \mathrm{H}$ of Hesperian clay minerals on Mars. Science 347, 412-414 (2015). doi:10.1126/science.1260291 Medline

60. L. E. Borg, J. N. Connelly, L. E. Nyquist, C. Y. Shih, H. Wiesmann, Y. Reese, The age of the carbonates in martian meteorite ALH84001. Science 286, 90-94 (1999). doi:10.1126/science.286.5437.90 Medline

61. T. J. Lapen, M. Righter, A. D. Brandon, V. Debaille, B. L. Beard, J. T. Shafer, A. H. Peslier, A younger age for ALH84001 and its geochemical link to shergottite sources in Mars. Science 328, 347-351 (2010). doi:10.1126/science.1185395 Medline

62. S. Hu, Y. Lin, J. Zhang, J. Hao, W. Xing, T. Zhang, W. Yang, H. Changela, Ancient geologic events on Mars revealed by zircons and apatites from the Martian regolith breccia NWA 7034. Meteorit. Planet. Sci. 54, 850-879 (2019). doi:10.1111/maps.13256

63. J. J. Barnes, F. M. McCubbin, A. R. Santos, J. M. D. Day, J. W. Boyce, S. P. Schwenzer, U. Ott, I. A. Franchi, S. Messenger, M. Anand, C. B. Agee, Multiple early-formed water reservoirs in the interior of Mars. Nat. Geosci. 13, 260-264 (2020). doi:10.1038/s41561-020-0552-y Medline

64. J. A. Grant, S. A. Wilson, N. Mangold, F. Calef III, J. P. Grotzinger, The timing of alluvial activity in Gale crater, Mars. Geophys. Res. Lett. 41, 1142-1149 (2014). doi:10.1002/2013GL058909

65. L. Le Deit, E. Hauber, F. Fueten, M. Pondrelli, A. P. Rossi, R. Jaumann, Sequence of infilling events in Gale Crater, Mars: Results from morphology, stratigraphy, and mineralogy. J. Geophys. Res. Planets 118, 2439-2473 (2013). doi:10.1002/2012JE004322
66. P. E. Martin, K. A. Farley, M. B. Baker, C. A. Malespin, S. P. Schwenzer, B. A. Cohen, P. R. Mahaffy, A. C. McAdam, D. W. Ming, P. M. Vasconcelos, R. Navarro-González, A Two-Step K-Ar Experiment on Mars: Dating the Diagenetic Formation of Jarosite from Amazzonian Groundwaters. J. Geophys. Res. Planets 122, 2803-2818 (2017). doi:10.1002/2017JE005445

67. P. R. Mahaffy et al., The sample analysis at Mars investigation and instrument suite. Space Sci. Rev. 170, 401-478 (2012). doi:10.1007/s11214-012-9879-z

68. K. L. Tanaka, S. J. Robbins, C. M. Fortezzo, J. A. Skinner Jr., T. M. Hare, The digital global geologic map of Mars: Chronostratigraphic ages, topographic and crater morphologic characteristics, and updated resurfacing history. Planet. Space Sci. 95, 11-24 (2014). doi:10.1016/i.pss.2013.03.006

69. S. L. Murchie, J. F. Mustard, B. L. Ehlmann, R. E. Milliken, J. L. Bishop, N. K Mckeown, E. Z. Noe Dobrea, F. P. Seelos, D. L. Buczkowski, S. M. Wiseman, R. E. Arvidson, J. J. Wray, G. Swayze, R. N. Clark, D. J. Des Marais, A. S. McEwen, J.-P. Bibring, A synthesis of Martian aqueous mineralogy after 1 Mars year of observations from the mars Reconnaissance Orbiter. J. Geophys. Res. Planets 114 , E00D06 (2009). doi:10.1029/2009JE003342

70. V. Z. Sun, R. E. Milliken, The geology of mineralogy of Ritchey crater, Mars: Evidence for post-Noachian clay formation. J. Geophys. Res. Planets 119, 810-836 (2015). doi:10.1002/2013JE004602

71. D. T. Vaniman et al., Mineralogy of a mudstone at Yellowknife Bay, Gale crater Mars. Science 343, 1243480 (2014). doi:10.1126/science.1243480 Medline

72. B. Sutter, A. C. McAdam, P. R. Mahaffy, D. W. Ming, K. S. Edgett, E. B. Rampe, J. L. Eigenbrode, H. B. Franz, C. Freissinet, J. P. Grotzinger, A. Steele, C. H. House, P. D. Archer, C. A. Malespin, R. Navarro-González, J. C. Stern, J. F. Bell, F. J. Calef, R. Gellert, D. P. Glavin, L. M. Thompson, A. S. Yen, Evolved gas analyses of sedimentary rocks and eolian sediment in Gale Crater, Mars: Results of the Curiosity rover's sample analysis at Mars instrument from Yellowknife Bay to the Namib Dune. J. Geophys. Res. Planets 122, 2574-2609 (2017). doi:10.1002/2016JE005225

73. N. H. Thomas, B. L. Ehlmann, W. Rapin, F. Rivera-Hernández, N. T. Stein, J. Frydenvang, T. Gabriel, P.-Y. Meslin, S. Maurice, R. C. Wiens, Hydrogen Variability in the Murray Formation, Gale Crater, Mars. J. Geophys. Res. Planets 125, JE006289 (2020). doi:10.1029/2019.JE006289 Medline

74. J. Audouard, F. Poulet, M. Vincendon, R. E. Milliken, D. Jouglet, J.-P. Bibring, B. Gondet, Y. Langevin, Water in the Martian regolith from OMEGA/Mars Express. J. Geophys. Res. Planets 119, 1969-1989 (2014). doi:10.1002/2014JE004649

75. S. Maurice, W. Feldman, B. Diez, O. Gasnault, D. J. Lawrence, A. Pathare, T. Prettyman, Mars Odyssey neutron data: 1. Data processing and models of waterequivalent-hydrogen distribution. J. Geophys. Res. Planets 116, E11008 (2011). doi:10.1029/2011JE003810

76. C. B. Agee, N. V. Wilson, F. M. McCubbin, K. Ziegler, V. J. Polyak, Z. D. Sharp, Y. Asmerom, M. H. Nunn, R. Shaheen, M. H. Thiemens, A. Steele, M. L. Fogel, R. Bowden, M. Glamoclija, Z. Zhang, S. M. Elardo, Unique meteorite from early Amazonian Mars: Water-rich basaltic breccia Northwest Africa 7034. Science 339, 780-785 (2013). doi:10.1126/science.1228858 Medline

77. M. Humayun, A. Nemchin, B. Zanda, R. H. Hewins, M. Grange, A. Kennedy, J.-P. Lorand, C. Göpel, C. Fieni, S. Pont, D. Deldicque, Origin and age of the earliest Martian crust from meteorite NWA 7533. Nature 503, 513-516 (2013). do:10.1038/nature12764Medline

78. L. Wernicke, B. Jakosky Quantifying the water stored in hydrated minerals on Mars. AGU Fall Meeting, \#P41C-3462 (2019).

79. E. Chassefière, F. Leblanc, Constraining methane release due to serpentinization by the observed D/H ratio on Mars. Earth Planet. Sci. Lett. 310, 262-271 (2011). doi:10.1016/i.epsl.2011.08.013

80. H. Kurokawa, T. Usui, M. Sato, Interactive evolution of multiple water-ice reservoirs on Mars: Insights from hydrogen isotope compositions. Geochem. J. 50, 67-79 (2016). doi:10.2343/geochemj.2.0407

81. R. Grimm, K. P. Harrison, D. E. Stillman, M. R. Kirchoff, On the secular retention of ground water and ice on Mars. J. Geophys. Res. Planets 122, 94-109 (2017) doi:10.1002/2016JE005132

82. J. Carter, F. Poulet, J.-P. Bibring, N. Mangold, S. Murchie, Hydrous minerals on Mars as seen by the CRISM and OMEGA imaging spectrometers: Updated global view. J. Geophys. Res. Planets 118, 831-858 (2013). doi:10.1029/2012JE004145 
83. R. M. Capuano et al., Evidence of fluid flow in microfractures in geopressured shales. AAPG Bull. 77, 1303-1314 (1993).

84. K. Hyeong, R. M. Capuano, Hydrogen isotope fractionation factor for mixed-layer illite/smectite at 60 to $150 \mathrm{C}$ : New data from the northeast Texas Gulf Coast. Geochim. Cosmochim. Acta 68, 1529-1543 (2004). doi:10.1016/i.gca.2003.10.002

85. S. M. F. Sheppard, H. A. Gilg, Stable isotope geochemistry of clay minerals. Clay Miner. 31, 1-24 (1996). doi:10.1180/claymin.1996.031.1.01

86. H. W. Yeh, D/H ratios and late-stage dehydration of shales during burial. Geochim. Cosmochim. Acta 44, 341-352 (1980)

87. J. R. Lawrence, H. P. Taylor Jr., Hydrogen and oxygen isotope systematics in weathering profiles. Geochim. Cosmochim. Acta 36, 1377-1393 (1972). doi:10.1016/0016-7037(72)90068-3

88. S. M. Savin, S. Epstein, The oxygen and hydrogen isotope geochemistry of clay minerals. Geochim. Cosmochim. Acta 34, 25-42 (1970). doi:10.1016/00167037(70)90149-3

89. S. A. Hauck, R. J. Phillips, Thermal and crustal evolution of Mars. J. Geophys. Res. Planets 107, 5052 (2002). doi:10.1029/2001JE001801

90. R. Greeley, B. D. Schneid, Magma generation on Mars: Amounts, rates, and comparisons with Earth, moon, and venus. Science 254, 996-998 (1991). doi:10.1126/science. 254.5034.996 Medline

91. M. Grott, D. Baratoux, E. Hauber, V. Sautter, J. Mustard, O. Gasnault, S. W. Ruff, S.I. Karato, V. Debaille, M. Knapmeyer, F. Sohl, T. Van Hoolst, D. Breuer, A. Morschhauser, M. J. Toplis, Long-term evolution of the Martian crust-mantle system. Space Sci. Rev. 174, 49-111 (2013). doi:10.1007/s11214-012-9948-3

92. A. Morschhauser, M. Grott, D. Breuer, Crustal recycling, mantle dehydration, and the thermal evolution of Mars. Icarus 212, 541-558 (2011) doi:10.1016/i.icarus.2010.12.028

93. H. Y. McSween Jr., R. P. Harvey, Outgassed water on Mars: Constraints from melt inclusions in SNC meteorites. Science 259, 1890-1892 (1993). doi:10.1126/science. 259.5103.1890 Medline

94. A. A. Fraeman, J. Korenaga, The influence of mantle melting on the evolution of Mars. Icarus 210, 43-57 (2010). doi:10.1016/i.icarus.2010.06.030

95. F. Gaillard, B. Scaillet, The sulfur content of volcanic gases on Mars. Earth Planet. Sci. Lett. 279, 34-43 (2009). doi:10.1016/i.epsl.2008.12.028

96. L. Schaefer, B. Fegley Jr., Redox states of initial atmospheres outgassed on rocky planets and planetesimals. Astrophys. J. 843, 120 (2017). doi:10.3847/15384357/aa784f

97. A. C. Plesa, N. Tosi, D. Breuer, Can a fractionally crystallized magma ocean explain the thermo-chemical evolution of Mars? Earth Planet. Sci. Lett. 403, 225-235 (2014). doi:10.1016/j.epsl.2014.06.034

98. M. H. Carr, J. W. Head III, Geologic history of Mars. Earth Planet. Sci. Lett. 294, 185-203 (2010). doi:10.1016/i.epsl.2009.06.042

99. P. Mane, R. Hervig, M. Wadhwa, L. A. J. Garvie, J. B. Balta, H. Y. McSween Jr. Hydrogen isotopic composition of the Martian mantle inferred from the newest Martian meteorite fall, Tissint. Meteorit. Planet. Sci. 51, 2073-2091 (2016). doi:10.1111/maps.12717

100. P. F. Dobson, S. Epstein, E. M. Stolper, Hydrogen isotope fractionation between coexisting vapor and, silicate glasses and melts at low pressure. Geochim. Cosmochim. Acta 53, 2723-2730 (1989). doi:10.1016/0016-7037(89)90143-9

101. A. R. Sarafian, E. H. Hauri, F. M. McCubbin, T. J. Lapen, E. L. Berger, S. G. Nielsen, H. R. Marschall, G. A. Gaetani, K. Righter, E. Sarafian, Early accretion of water and volatile elements to the inner Solar System: Evidence from angrites. Philos. Trans. A Math. Phys. Eng. Sci. 375, 20160209 (2017). doi:10.1098/rsta.2016.0209 Medline

102. J. M. D. Day, K. T. Tait, A. Udry, F. Moynier, Y. Liu, C. R. Neal, Martian magmatism from plume metasomatized mantle. Nat. Commun. 9, 4799 (2018). doi:10.1038/s41467-018-07191-0 Medline

103. D. Baratoux, M. J. Toplis, M. Monnereau, V. Sautter, The petrological expression of early Mars volcanism. J. Geophys. Res. Planets 118, 59-64 (2013). doi:10.1029/2012JE004234

104. S. W. Stone, R. V. Yelle, M. Benna, D. Y. Lo, M. K. Elrod, P. R. Mahaffy, Hydrogen escape from Mars is driven by seasonal and dust storm transport of water. Science 370, 824-831 (2020). doi:10.1126/science.aba5229 Medline
105. N. G. Heavens, A. Kleinböhl, M. S. Chaffin, J. S. Halekas, D. M. Kass, P. O. Hayne, D. J. McCleese, S. Piqueux, J. H. Shirley, J. T. Schofield, Hydrogen escape from mars enhanced by deep convection in dust storms. New Astron. 2, 126-132 (2018). doi:10.1038/s41550-017-0353-4

106. M. S. Chaffin, J. Deighan, N. M. Schneider, A. I. F. Stewart, Elevated atmospheric escape of atomic hydrogen from mars induced by high-altitud6e water. Nat. Geosci. 10, 174-178 (2017). doi:10.1038/ngeo2887

107. D. Bhattacharyya, J. T. Clarke, J.-L. Bertaux, J.-Y. Chaufray, M. Mayyasi, A strong seasonal dependence in the Martian hydrogen exosphere. Geophys. Res. Lett. 42. 8678-8685 (2015). doi:10.1002/2015GL065804

108. Y. L. Yung, W. B. DeMore, Photochemistry of Planetary Atmospheres (Oxford University Press, Oxford, UK, 1998).

109. A. S. Ackerman, M. S. Marley, Precipitating condensation clouds in substellar atmosphere. Astrophys. J. 556, 872-884 (2001). doi:10.1086/321540

110. R. M. Haberle, Solar system/syn, atmospheres, evolution of atmospheres | Planetary Atmospheres: Mars, in Encyclopedia of Atmospheric Sciences (Elsevier, ed. 2, 2015), pp. 168-177.

111. R. T. Clancy, B. J. Sandor, M. J. Wolff, P. R. Christensen, M. D. Smith, J. C. Pearl B. J. Conrath, R. J. Wilson, An intercomparison of ground-based millimeter, MGS, TES, and Viking atmospheric temperature measurements: Seasonal and interannual variability of temperatures and dust loading in the global Mars atmosphere. J. Geophys. Res. 105 (E4), 9553-9571 (2000). doi:10.1029/1999JE001089

112. A. Seiff, Structure of the atmospheres of Mars and Venus below 100 kilometers. Adv. Space Res. 7, 5-16 (1987). doi:10.1016/0273-1177(87)90196-7

113. M. W. Claire, J. Sheets, M. Cohen, I. Ribas, V. S. Meadows, D. C. Catling, The evolution of solar flux from $0.1 \mathrm{~nm}$ to $160 \mu \mathrm{m}$ : Quantitative estimates for planetary studies. Astrophys. J. 757, 95 (2012). do::10.1088/0004-637X/757/1/95

114. R. Wordsworth, Y. Kalugina, S. Lokshtanov, A. Vigasin, B. Ehlmann, J. Head, C. Sanders, H. Wang, Transient reducing greenhouse warming on early Mars. Geophys. Res. Lett. 44, 665-671 (2017). doi:10.1002/2016GL071766

115. W. K. Hartmann, Martian cratering 8: Isochron refinement and the chronology of Mars. Icarus 174, 294-320 (2005). doi:10.1016/i.icarus.2004.11.023

116. E. Chassefière, B. Langlais, Y. Quesnel, F. Leblanc, The fate of early Mars' lost water: The role of serpentinization. J. Geophys. Res. Planets 118, 1123-1134 (2013). doi:10.1002/igre.20089

117. A. W. Heard, E. S. Kite, A probabilistic case for a large missing carbon sink on Mars after 3.5 billion years ago. Earth Planet. Sci. Lett. 531, 116001 (2020) doi:10.1016/i.epsl.2019.116001

118. G. J. Taylor, L. M. V. Martel, S. Karunatillake, O. Gasnault, W. V. Boynton, Mapping Mars geochemically. Geology 38, 183-186 (2010). doi:10.1130/G30470.1

119. H. Y. McSween, S. W. Ruff, R. V. Morris, J. F. Bell III, K. Herkenhoff, R. Gellert, K. R. Stockstill, L. L. Tornabene, S. W. Squyres, J. A. Crisp, P. R. Christensen, T. J. McCoy, D. W. Mittlefehldt, M. Schmidt, Alkaline volcanic rocks from the Columbia Hills, Gusev crater, Mars. J. Geophys. Res. Planets 111, E09S91 (2006). doi:10.1029/2006JE002698

120. R. V. Morris, G. Klingelhöfer, C. Schröder, D. S. Rodionov, A. Yen, D. W. Ming, P. A. de Souza Jr., I. Fleischer, T. Wdowiak, R. Gellert, B. Bernhardt, E. N. Evlanov, B. Zubkov, J. Foh, U. Bonnes, E. Kankeleit, P. Gütlich, F. Renz, S. W. Squyres, R. E. Arvidson, Mössbauer mineralogy of rock, soil, and dust at Gusev crater, Mars: Spirit's journey through weakly altered olivine basalt on the plains and pervasively altered basalt in the Columbia Hills. J. Geophys. Res. Planets 111, E2 (2006). doi:10.1029/2005JE002584

121. B. L. Ehlmann, K. S. Edgett, B. Sutter, C. N. Achilles, M. L. Litvak, M. G. A. Lapotre, R. Sullivan, A. A. Fraeman, R. E. Arvidson, D. F. Blake, N. T. Bridges, P. G. Conrad A. Cousin, R. T. Downs, T. S. J. Gabriel, R. Gellert, V. E. Hamilton, C. Hardgrove, J. R. Johnson, S. Kuhn, P. R. Mahaffy, S. Maurice, M. McHenry, P.-Y. Meslin, D. W. Ming, M. E. Minitti, J. M. Morookian, R. V. Morris, C. D. O'Connell-Cooper, P. C. Pinet, S. K. Rowland, S. Schröder, K. L. Siebach, N. T. Stein, L. M. Thompson, D. T. Vaniman, A. R. Vasavada, D. F. Wellington, R. C. Wiens, A. S. Yen, Chemistry, mineralogy, and grain properties at Namib and High dunes, Bagnold dune field, Gale crater, Mars: A synthesis of Curiosity rover observations. J. Geophys. Res. Planets 122, 2510-2543 (2017). doi:10.1002/2017JE005267Medline 


\section{ACKNOWLEDGMENTS}

We thank A. Hoffmann, P. Mahaffey, C. Webster, H. Franz, J. Stern, D. Breuer, J.

Dickson, J. Eiler, J. Grotzinger, Y. Liu, E. Stolper, and the Sample Analysis at Mars (SAM) Science Team for discussion. We thank B. Jakosky, two anonymous referees, and editor K. Smith for suggestions that strengthened the manuscript. Funding: R.H., B.L.E. and Y.L.Y were supported by a NASA Habitable Worlds grant (\#NNN13D466T, later changed to \#80NM0018F0612). Part of this work was carried out at the Jet Propulsion Laboratory, California Institute of Technology, under a contract with the National Aeronautics and Space Administration (grant 80NM0018D0004). E.L.S. was supported by a NASA Earth and Space Science Fellowship (NESSF) (grant \#80NSSC18K1255). D.J.A. was supported by a Future Investigator in NASA Earth and Space Science and Technology (FINESST) fellowship (grant \#80NSSC19K1548). Author contributions: E.L.S. drafted the manuscript, developed the code and performed the simulations for the D/H model. B.L.E. developed the concept of the water budget and D/H model. E.L.S., B.L.E., and R.H. developed the D/H model concept. E.L.S., B.L.E., R.H., D.J.A., and Y.L.Y adapted the Kinetics model input parameters for this study. D.J.A. implemented the Kinetics adaption and D.J.A and Y.L.Y. analyzed the Kinetics output. All authors participated in the writing and editing of the manuscript. Competing interests: We declare no competing interests. Data and materials available: The equations used for the D/H model, and our adopted parameter ranges are given in the supplementary material. The Mars D/H model code, input and output files, the Kinetics data files used for fig. S3, and visualization scripts are all available in the CaltechDATA repository at DOl: 10.22002/D1.1879. The Kinetics software was developed by a combination of authors (D.J.A. and Y.L.Y.) and a large number of non-authors $(25,26)$, so we do not have permission to distribute the source code. An executable version with adjustable input parameters, to reproduce all simulation scenarios in this paper, is available at the same DOI. The SAM data were taken from the Planetary Data System at https://pds-geosciences. wustl.edu/ms//msl-m-sam-2-rdr-10$\mathrm{v} 1 / \mathrm{ms} / \mathrm{sam} 1 \mathrm{xxx} /$ data/; we used level 2 data for samples eid25094, eid25123, eid25173, eid25413, eid25484, eid25515, and eid25538 (5).

SUPPLEMENTARY MATERIALS

science.sciencemag.org/cgi/content/full/science.eabc7717/DC1

Materials and Methods

Supplementary Text

Tables S1 to S3

Figs. 51 to 56

References (48-121)

11 June 2020; accepted 4 March 2021

Published online 16 March 2021

10.1126/science.abc7717 


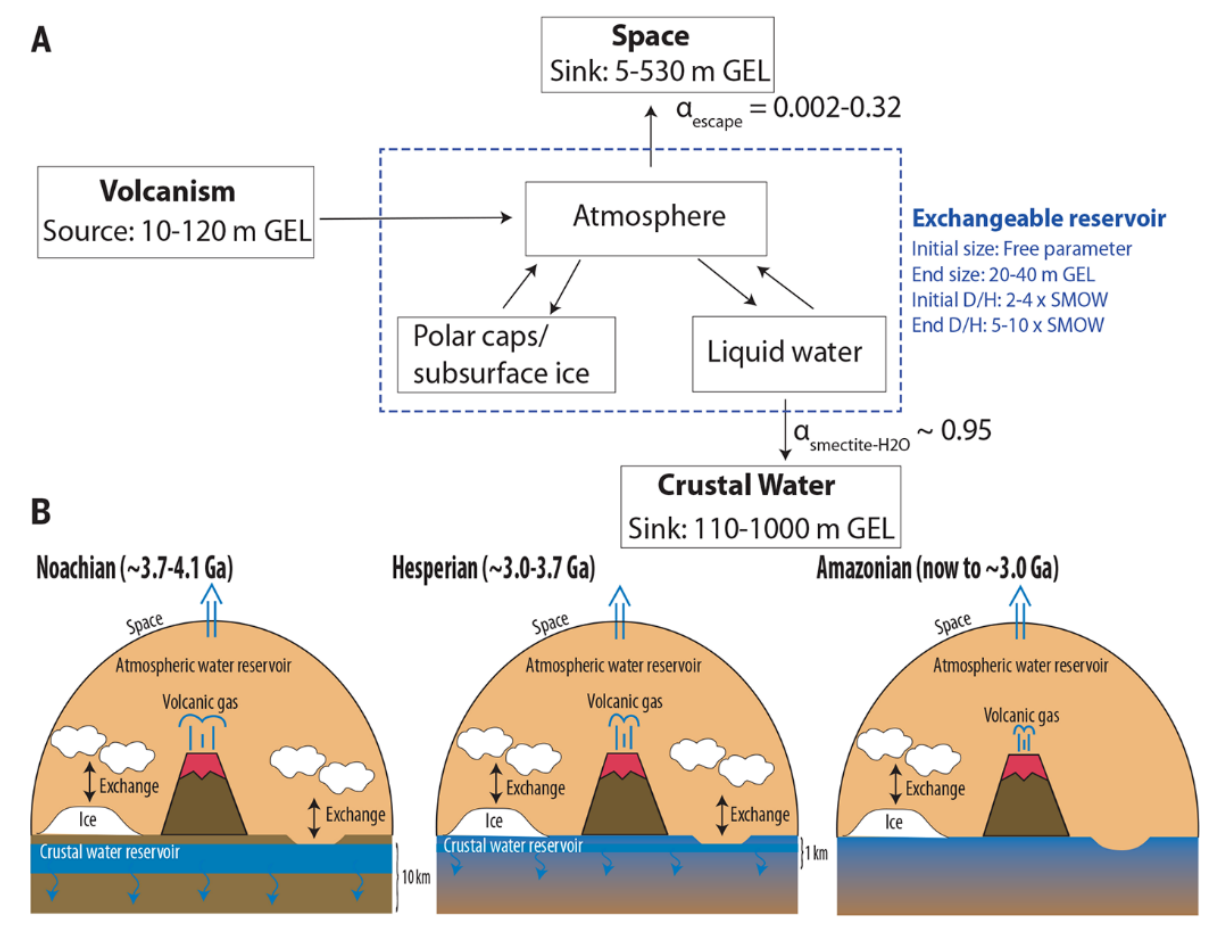

Fig. 1. Schematic illustration of water sink and source fluxes considered in our simulations. (A) Box model representation with ranges of integrated water sinks, sources, reservoir sizes, and fractionation factors adopted in our simulations. The crustal water reservoir is based on rover and remote sensing observations and represents all unexchangeable subsurface ice, liquid water, and structural water in minerals (5). The integrated amount of $\mathrm{H}$ escape to space is based on measurements of the current flux and KINETICS calculations of fluxes (figs. S2 and S3). The integrated volcanic degassing is based on thermochemical models $(5,24)$. The blue box indicates the exchangeable reservoir, with its properties in blue text. (B) Schematic representation of our assumptions for the Noachian, Hesperian, and Amazonian periods. During the Noachian, the fluxes associated with crustal hydration and volcanic degassing are high. These all reduce during the Hesperian. During the Amazonian, volcanic degassing falls further and there is negligible crustal hydration as water is predominantly solid ice. 


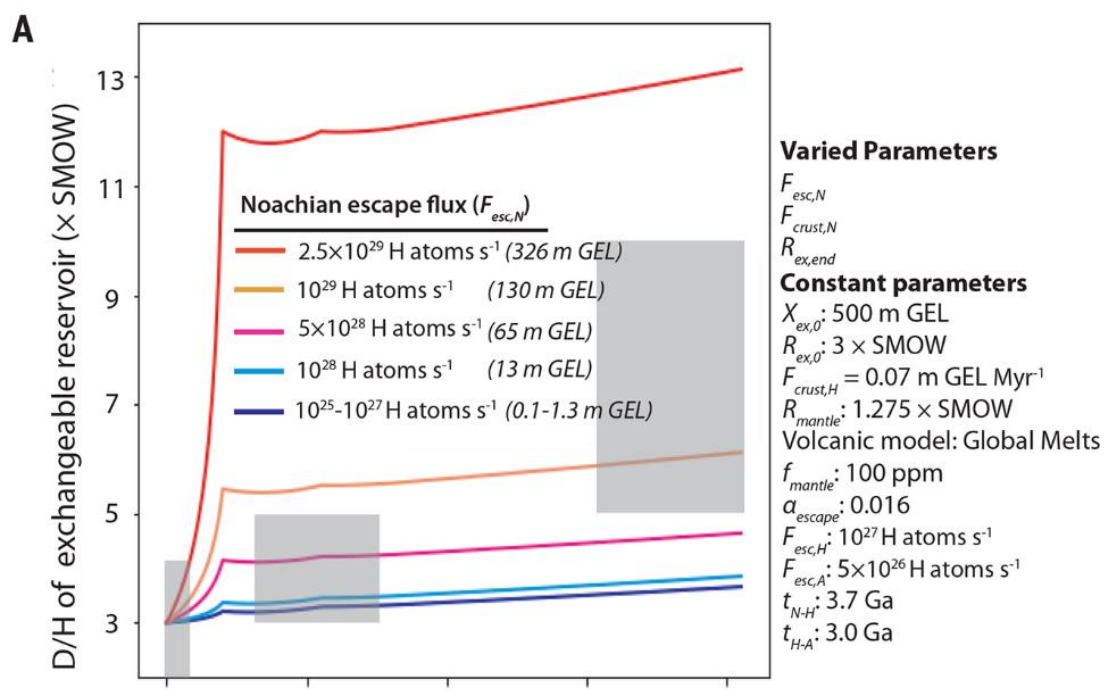

Fig. 2. Simulated $\mathrm{D} / \mathrm{H}$ evolution for different assumptions of crustal hydration and atmospheric escape rates. Each panel shows the evolution of the $\mathrm{D} / \mathrm{H}$ ratio of the exchangeable reservoir in our simulation. Most parameters, including $X_{\text {ex,o, }}$ are fixed; $R_{\text {ex,end }}$ is a free parameter to visualize the model sensitivity. The colored lines show results for different assumptions of the flux rates. The large range of $\mathrm{D} / \mathrm{H}$ measurements from meteorite, rover, and telescope observations are shown with grey rectangles (fig. S1). (A) Effects of increasing the Noachian escape flux $\left(F_{\text {esc,N }}\right)$. (B) Effects of increasing the Hesperian escape flux $\left(F_{\text {esc.H }}\right)$. (C) Effects of increasing the Noachian ( $\left.F_{\text {crust,N }}\right)$ and Hesperian $\left(F_{\text {crust.H }}\right)$ crustal hydration fluxes. When $F_{\text {crust, N }}$ increases, the exchangeable reservoir becomes smaller, inducing larger fractionations during the Noachian. When $F_{\text {crust.H }}$ increases, the allowed values of $F_{\text {crust, N }}$ decrease, causing less fractionation during the Noachian.

\section{C}

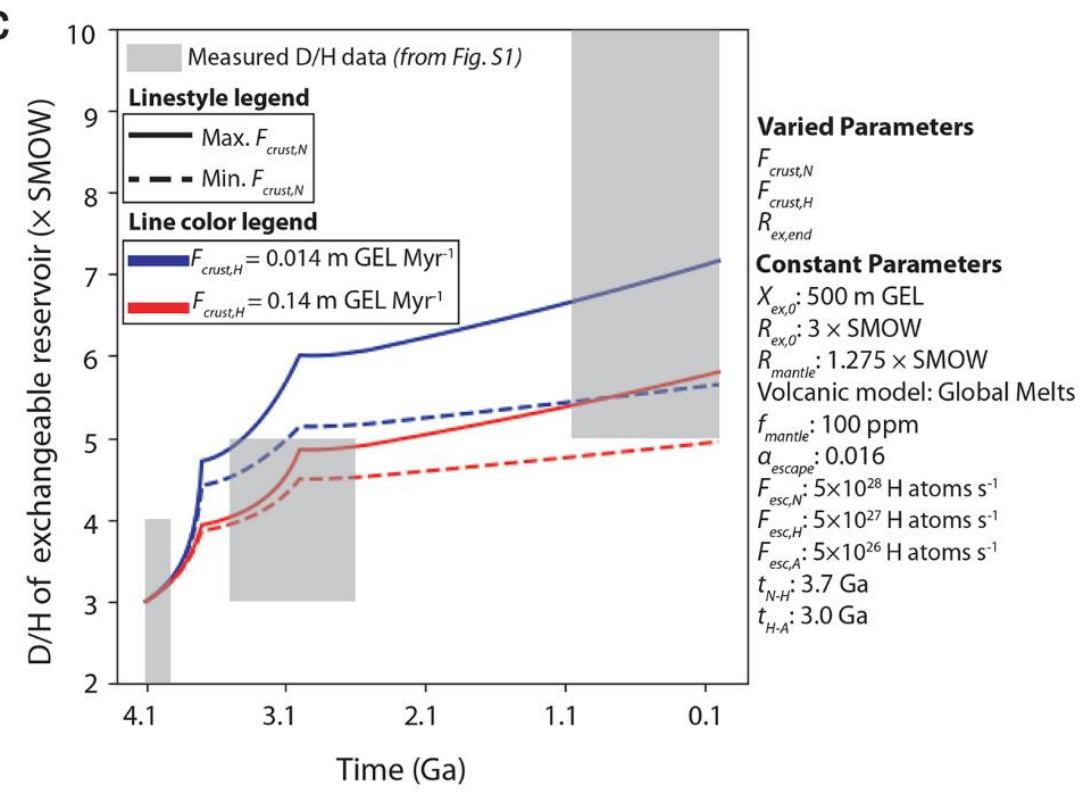

Varied Parameters $F_{\text {esc }, H}$ $F_{\text {crust, N }}$ Constant parameters $X_{\text {ex, }}: 500 \mathrm{~m} \mathrm{GEL}$ $R_{\text {ex, } 0.0}^{e x}: 3 \times$ SMOW $F_{\text {crust, }, \mathrm{H}}=0.07 \mathrm{~m} \mathrm{GEL} \mathrm{Myr}^{-1}$ $R_{\text {mantie }}^{\text {crust, }}: 1.275 \times \mathrm{SMOW}$ Volcanic model: Global Melts $f_{\text {mantle }}: 100 \mathrm{ppm}$

$a_{\text {escape }}: 0.016$ $F_{\text {esc }, \mathrm{N}} 5 \times 10^{28} \mathrm{H}^{2}$ atoms s-1 $F_{\text {esc. }}: 5 \times 10^{26} \mathrm{H}^{2}$ atoms s $\mathrm{s}^{-1}$ $t_{\mathrm{N}-\mathrm{H}}: 3.7 \mathrm{Ga}$ $t_{H-A}: 3.0 \mathrm{Ga}$ 

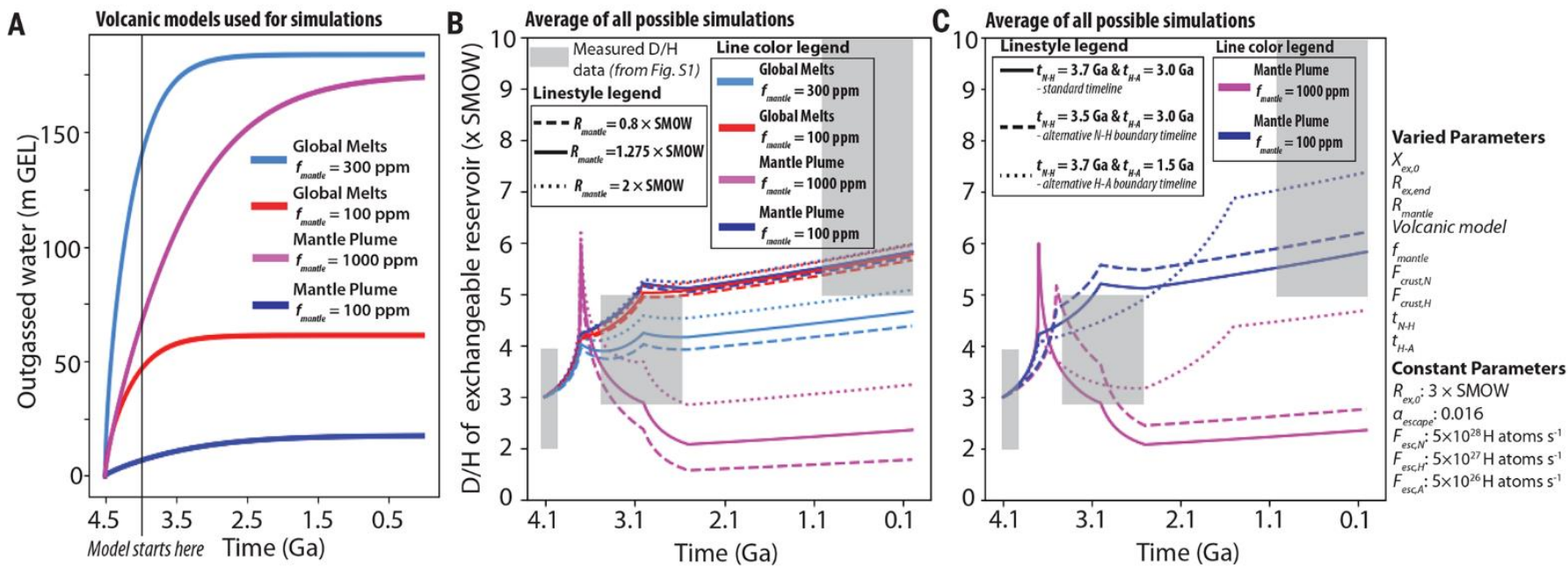

Fig. 3. Simulated D/H evolution for different assumptions of the volcanic outgassing as a function of time. (A) Adopted volcanic models $(5,24)$. The Mantle Plume model $(24)$ assumes an initial mantle water content $\left(f_{\text {mantle }}\right)$ of 100 ppm (dark blue) or 1000 ppm (fuchsia). The alternative Global Melts model (24) assumes $f_{\text {mantle }}$ is 100 ppm (red) or $300 \mathrm{ppm}$ (light blue). (B) The evolution of the D/H ratio in the exchangeable reservoir from an average of simulations with each assumed volcanic model. Line colors are the same as panel A, grey boxes are the same as in Fig. 2. Line styles refer to assumed D/H composition of volcanic gas [dashed: $0.8 \times$ SMOW (27), solid: $1.275 \times$ SMOW (47), dotted: $2 \times$ SMOW (19)]. (C) Evolution of the D/H ratio in the exchangeable reservoir for average of simulations with different assumptions of volcanic model and age of the Noachian/Hesperian boundary $\left(t_{\mathrm{N}-\mathrm{H}}\right)$ and the Hesperian/Amazonian boundary $\left(t_{H-A}\right)(5)$. These transition ages control when $F_{\text {esc }}$ and $F_{\text {crust }}$ values change under our assumptions for the Noachian, Hesperian, and Amazonian periods (5). Line colors are the same as panel A. Line styles refer to the assumed timing of $t_{\mathrm{N}-\mathrm{H}}$ and $t_{\mathrm{H}-\mathrm{A}}$ (solid: standard boundary ages where $t_{\mathrm{N}-\mathrm{H}}$ is $3.7 \mathrm{Ga}$ and $t_{\mathrm{H}-\mathrm{A}}$ is 3.0 $\mathrm{Ga}$, dashed: $t_{\mathrm{N}-\mathrm{H}}$ is moved to $3.5 \mathrm{Ga}$, dotted: $t_{\mathrm{H}-\mathrm{A}}$ is moved to $1.5 \mathrm{Ga}$ ). In these simulations $R_{\text {ex, end }}$ is allowed to vary. 

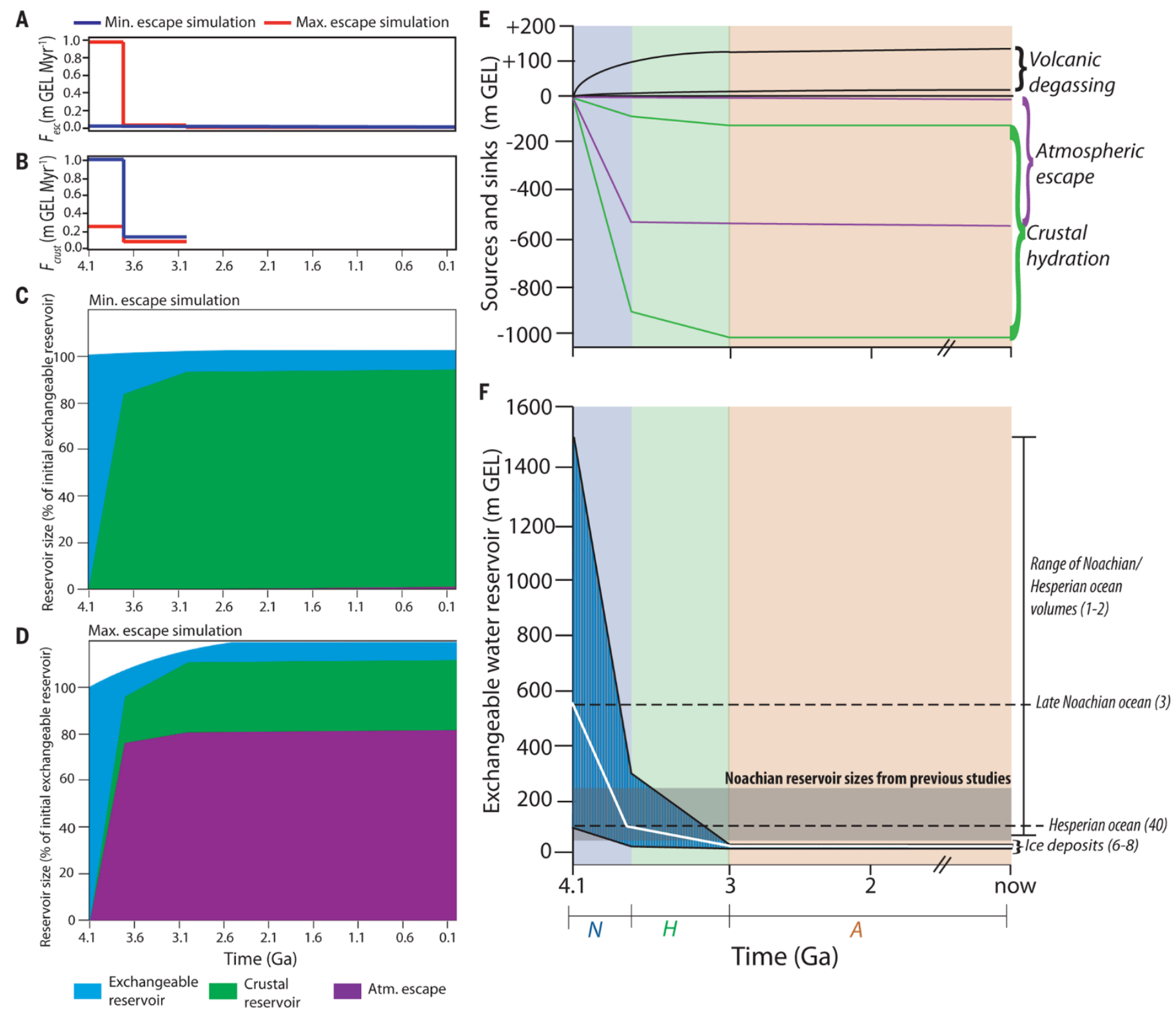

Fig. 4. Compilation of relative reservoir sizes through time from all our simulations. (A to D) Model simulations with min. and max. possible atmospheric escape fluxes $\left(F_{\text {esc }}\right)$ and crustal hydration fluxes $\left(F_{\text {crust }}\right)$ within allowed parameter space and simulation constraints, where the exchangeable reservoir D/H of 5-10 $\times$ SMOW must be reproduced. (A) Evolution of min. (blue line) and max. (red line) $F_{\text {esc }}$ within the constrained simulation space through geological time. (B) Evolution of min. (red line) and max. (blue line) $F_{\text {crust }}$ within the constrained simulation space through geological time. $[(C)$ and $(D)]$ Size evolution of three simulated reservoirs through geological time shown as cumulative percentage. Colored areas show the time evolution within the exchangeable reservoir (blue), crustal reservoir (green), and water escaped to the atmosphere (purple). (C) shows the scenario where $F_{\text {esc }}$ is minimized and $F_{\text {crust }}$ is maximized, while (D) shows the opposite scenario. (E) Upper and lower bounds on sources and sinks from Fig. 1 through time derived from our simulations (5) (black: volcanic degassing source, green: crustal hydration sink, purple: atmospheric escape sink). (F) The range of exchangeable reservoir sizes (teal) permitted by our simulations. For comparison, we show the reservoirs derived by previous studies $(4,11,14,15)$ (grey rectangle) and ocean sizes based on geomorphological evidence $(1-3,40)$ (dashed lines). Our preferred simulation scenario is shown as a solid white line. Noachian (N), Hesperian (H), and Amazonian (A) time intervals used in model are shaded in blue, green, and red respectively. 
Table 1. Summary of parameters assumed or calculated in our preferred scenario. We list the assumed parameter values for our preferred simulation (Fig. 4F) and our reasoning for each choice. This preferred simulation reproduces a D/H composition $\sim 5.3 \times$ SMOW for the present-day atmosphere and an initial exchangeable reservoir size of $\sim 570 \mathrm{~m}$ GEL.

\begin{tabular}{|c|c|c|c|c|}
\hline Variable & Meaning & Value & Units & Reasoning \\
\hline \multicolumn{5}{|l|}{ Calculated } \\
\hline$R_{\text {ex,end }}$ & $\begin{array}{l}\text { D/H of present-day ex- } \\
\text { changeable reservoir }\end{array}$ & $\begin{array}{l}\sim 5.3 \times \\
\text { SMOW }\end{array}$ & N/A & $\begin{array}{l}\text { Calculated result of our preferred } \\
\text { model }\end{array}$ \\
\hline$X_{\mathrm{ex}, 0}$ & $\begin{array}{l}\text { Initial size of exchangeable } \\
\text { reservoir }\end{array}$ & $\sim 570$ & m GEL & $\begin{array}{l}\text { Calculated result of our preferred } \\
\text { model }\end{array}$ \\
\hline \multicolumn{5}{|l|}{ Assumed } \\
\hline$R_{\mathrm{ex}, 0}$ & $\begin{array}{l}\text { Initial } \mathrm{D} / \mathrm{H} \text { of exchangea- } \\
\text { ble reservoir }\end{array}$ & $4 \times \mathrm{SMOW}$ & N/A & $\begin{array}{l}\text { D/H measurements of ALH84001 } \\
\text { (13) }\end{array}$ \\
\hline$R_{\text {mantle }}$ & $\mathrm{D} / \mathrm{H}$ of mantle & $\begin{array}{l}1.275 \times \\
\text { SMOW }\end{array}$ & N/A & $\begin{array}{l}\mathrm{D} / \mathrm{H} \text { measurements of meteorites } \\
(47)\end{array}$ \\
\hline$\alpha_{\text {smectite- } \mathrm{H}_{2} \mathrm{O}}$ & $\begin{array}{l}\mathrm{D} / \mathrm{H} \text { fractionation factor } \\
\text { between smectite and wa- } \\
\text { ter }\end{array}$ & 0.95 & N/A & $\begin{array}{l}\text { Literary review of geochemical ex- } \\
\text { periments } \\
\text { (table S2) (5) }\end{array}$ \\
\hline$\alpha_{\text {escape }}$ & $\begin{array}{l}\mathrm{D} / \mathrm{H} \text { fractionation factor of } \\
\text { atmospheric escape }\end{array}$ & 0.16 & N/A & Photochemical model result (29) \\
\hline$X_{\text {ex,end }}$ & $\begin{array}{l}\text { Present-day size of ex- } \\
\text { changeable reservoir }\end{array}$ & 20 to 40 & m GEL & $\begin{array}{l}\text { A range of remote sensing evidence } \\
\text { (5) }\end{array}$ \\
\hline$F_{\text {crust,N }}$ & $\begin{array}{l}\text { Rate of water drawdown } \\
\text { by crustal hydration during } \\
\text { the Noachian }\end{array}$ & 1.25 & $\begin{array}{l}\mathrm{m} \mathrm{GEL} \\
\mathrm{Myr}^{-1}\end{array}$ & $\begin{array}{l}\text { Intermediate value based on remote } \\
\text { sensing evidence }(5,18)\end{array}$ \\
\hline$F_{\text {crust,H }}$ & $\begin{array}{l}\text { Rate of water drawdown } \\
\text { by clay formation during } \\
\text { the Hesperian }\end{array}$ & 0.07 & $\begin{array}{l}\mathrm{m} \text { GEL } \\
\mathrm{Myr}^{-1}\end{array}$ & $\begin{array}{l}\text { Intermediate value based on remote } \\
\text { sensing evidence }(5,18)\end{array}$ \\
\hline$f_{\text {mantle }}$ & Water content of mantle & 100 & ppm & $\begin{array}{l}\text { Most commonly adopted meteorite } \\
\text { measurements }(5,24)\end{array}$ \\
\hline$F_{\text {volcanic }}$ & $\begin{array}{l}\text { Rate of volcanic degassing } \\
\text { of } \mathrm{H}_{2} \mathrm{O}\end{array}$ & $\begin{array}{l}\text { Time-de- } \\
\text { pendent } \\
\text { fluxes, see } \\
\text { text }\end{array}$ & $\begin{array}{l}\mathrm{m} \mathrm{GEL} \\
\mathrm{Myr}^{-1}\end{array}$ & $\begin{array}{l}\text { Compiled from two thermal evolu- } \\
\text { tion models }(24)\end{array}$ \\
\hline$F_{\text {volcanic,A }}$ & $\begin{array}{l}\text { Rate of volcanic produc- } \\
\text { tion after } 2.5 \mathrm{Ga}\end{array}$ & $2 \times 10^{-4}$ & $\begin{array}{l}\mathrm{m} \text { GEL } \\
\mathrm{Myr}^{-1}\end{array}$ & $\begin{array}{l}\text { Geological remote sensing evidence } \\
\text { (5) }\end{array}$ \\
\hline$F_{\text {esc }, \mathrm{A}}$ & Present-day H escape flux & $5 \times 10^{26}$ & $\mathrm{H}$ atoms s $\mathrm{s}^{-1}$ & Spacecraft measurements $(5,16)$ \\
\hline$F_{\mathrm{esc}, \mathrm{N}}$ & $\begin{array}{l}\text { H escape flux during the } \\
\text { Noachian }\end{array}$ & $10^{27}$ & $\mathrm{H}_{\text {atoms s }}{ }^{-1}$ & $\begin{array}{l}\text { Modeled in this study (Fig. S2-S3) } \\
\text { (5) }\end{array}$ \\
\hline$F_{\text {esc }, \mathrm{H}}$ & $\begin{array}{l}\text { H escape flux during the } \\
\text { Hesperian }\end{array}$ & $10^{27}$ & $\mathrm{H}_{\text {atoms s }}{ }^{-1}$ & $\begin{array}{l}\text { Modeled in this study (Fig. S2-S3) } \\
\text { (5) }\end{array}$ \\
\hline$t_{\mathrm{N}-\mathrm{A}}$ & $\begin{array}{l}\text { End of deep, "Noachian" } \\
\text { crustal alteration }\end{array}$ & 3.7 & $\mathrm{Ga}$ & Most commonly adopted age (5) \\
\hline$t_{\mathrm{H}-\mathrm{A}}$ & $\begin{array}{l}\text { End of shallow, "Hespe- } \\
\text { rian" } \\
\text { crustal alteration }\end{array}$ & 3.0 & $\mathrm{Ga}$ & Most commonly adopted age (5) \\
\hline
\end{tabular}

